This is a preprint of: Morgan, H., Nolte, L., Rishworth, B. \& Stevens, C. (In press) "My children are my world": raising the voices of birth mothers with substantial experience of counselling following the loss of their children to adoption or foster care, Adoption and Fostering.

\title{
"My children are my world": Raising the voices of birth mothers with substantial experience of counselling following the loss of their children to adoption or foster
}

\section{care}

\author{
Hannah C. M. Morgan \\ University of Hertfordshire, UK \\ Lizette Nolte
}

University of Hertfordshire, UK

\section{Barbara Rishworth}

Re Frame, UK

\section{Clarissa Stevens}

Birth Mother, Activist, UK

\section{Abstract}

There is very little published literature on 'what works' in terms of support for birth mothers following the loss of their children to compulsory adoption or foster care. The aim of this paper is to raise the voices of a group of birth mothers, an historically stigmatised, powerless and neglected group, with substantial experience of such counselling. A user of services and expert by experience was recruited to join the research team and was consulted at all stages of the research process. Five birth mothers were interviewed regarding their experiences of counselling with a counselling service for birth relatives post-child removal. These interviews were systematically analysed using an IPA methodology through the lens of the research question: What are the experiences of birth mothers who engage in person-centred counselling following the loss of a child or children to compulsory adoption or foster care? Three master themes were constructed from the data, namely From feeling alone, judged and let down...to feeling part of a special relationship, "The Healing Process" and "My Children are my world". The clinical invitations extended by these findings are discussed.

\section{Key words}

Birth mothers, adoption, foster care, care proceedings, counselling, therapeutic relationship, identity, service user involvement 


\section{Introduction}

This study explored the experiences of birth mothers with substantial experience of counselling following the loss of their children to compulsory adoption or foster care. Historically, relinquishing birth mothers have been subject to significant social stigma and 'illegitimacy'. Their pregnancy and the removal of their children were often not discussed within their families or communities, and little or no support was available from helping professionals (Carr, 2007). Mothers were encouraged to 'act as though nothing unusual has happened' (Scourfield et al., 1991). In the UK, the 2002 Adoption and Children Act increased birth relatives' rights to support services when their children are adopted (Department of Health, 2001). However, this guidance has been interpreted and implemented inconsistently and it is unclear to what extent it has translated into meaningful support and services for birth relatives, or how these services are experienced by those accessing them (Selleck, 2007).

Several studies have highlighted the long-term psychological distress, 'unease', mental health difficulties, ongoing anger and guilt, shame, and grief of birth mothers forced to relinquish their children involuntarily (Baum \& Burn, 2007; Broadhurst \& Mason, 2013; Fravel, McRoy and Grotevant, 2000; Henderson, Sass and Carlson, 2007; Logan, 1996; Memarnia et al., 2015; Neil, 2006; Neil, 2013). Considering a social model of psychological distress, Neil (2013) links how birth mothers' experiences of trauma, powerlessness and isolation from social support could lead to psychological difficulties such as anxiety, depression, hearing voices and self-harm. Coupled with this, the distressing, adversarial and disempowering nature of court proceedings for birth parents is also widely acknowledged (Broadhurst \& Mason, 2017; Cossar \& Neil, 2010; Henderson et al., 2007).

Support services for birth mothers are important not only for the welfare of the parent. It is now usual in England for some form of contact between birth relatives and adopted children to be included in the adoption plan (Neil, 2000). Parent-child contact is considered important because of its effects on children's psychological identity and wellbeing (Salveron, Lewig and Arney, 2009). Given this ongoing contact, supporting the wellbeing of birth mothers is also in the interest of the child (Cossar \& Neil, 2010). Furthermore, the important work of Karen Broadhurst and her colleagues in England has shone a light on the high prevalence of repeat appearances of women in the family court. They cite this as evidence of the importance of building an evidence base and professional expertise such that this population of parents can benefit from effective mental health intervention, which addresses the complex psycho-social consequences of child removal and can potentially prevent such repeat child removals (Broadhurst \& Mason, 2017).

Despite this, there is very little published research or clinical literature concerning support services for birth mothers. Some have explained the lack of professional and academic consideration of the lives and situations of birth mothers as a consequence of the stigma of having children removed from your care (Slettebø, 2013). Logan suggests 
that it is related to the idea that birth mothers are "deemed to have wronged, need to be punished and therefore are not worthy of attention" (1996, p.610).

In her study Contact After Adoption Neil (2006) found very few of the birth relatives had received any support to deal with their feelings about the removal of their children. Also, despite evidence of high levels of mental distress, only a minority of birth relatives receive specialist mental health services (Henderson et al., 2007). Those who did access generic mental health 'talking therapies' reported that adoption issues were not addressed and therefore they had not found the intervention helpful (Neil et al., 2010). Cossar and Neil (2010) found that whilst agencies in England and Wales were relatively good at providing or commissioning independent support services, they were less successful at monitoring the quality of these services or how successful they were at engaging with birth relatives. The literature highlights many barriers that may exist for birth relatives trying to access support post-adoption. These include strong feelings of unworthiness and guilt, as well as feelings of anger and distrust of those in authority (Neil, 2006).

As yet there is no evidence of 'what works' in terms of support for birth relatives. Neil et al. (2010) identified some features of support in general that were valued by birth relatives, including 'relationship-based support' and 'flexibility' of approach (p. 115/123). Broadhurst and Mason (2013) cite anecdotal evidence that many women manage to successfully turn their lives around and go on to parent children, but note that the details of what led to their recovery is unavailable. Both individual counselling and group support have been found to be useful ways to diminish birth relatives' sense of failure and isolation (e.g. Charlton et al., 1998; Post-Adoption Centre, 2000). The small amount of literature that is available clearly points to the idea that birth mothers and other relatives benefit from timely and empathic counselling from adoption-competent therapists (Brodzinsky \& Smith, 2014).

It is clear that there is an urgent need for more evidence of what birth mothers find helpful and to hear the voices of birth mothers themselves regarding their experiences of support following child removal. Therefore, the current research aims to gain an understanding of birth mothers' experiences of counselling.

\section{Methodology}

This study aimed to answer the research question: What are the experiences of birth mothers who engage in person-centred counselling following the loss of a child or children to compulsory adoption or foster care? Full ethical approval was granted by the University of Hertfordshire Health, Science, Engineering and Technology Ethics Committee with Delegated Authority. 
As well as listening to and communicating the actual words of the research participants, it was felt that the research needed to go further to achieve a shift in the balance of power with this often disadvantaged and stigmatised group. As the Research Governance Framework for Health and Social Care (Department of Health, 2009) states: '[r]elevant service users and carers or their representative groups should be involved wherever possible in the design, conduct, analysis and reporting of research' $(2009$, p. 8). To this end an expert by experience who had experienced counselling following the loss of her children to adoption (although not connected to the adoption agency providing the counselling in this study) was recruited to the research team and was involved at all stages of the study from design, through recruitment and analysis, to dissemination.

Great care and thought was put in to recruiting the right person acknowledging the potentially alienating language and systems of academic research. A service user was found who had already begun a journey from user of services, to peer supporter, to trainer of trainers and activist. On meeting with her for the first time it was felt that she had much more to offer than just 'consultation' and so the decision was made to include her in the supervisory team as another research supervisor. This also served to redistribute power more evenly amongst the research team.

Including a service user in this way was not without its challenges. The systems in place for paying of expenses and access to university facilities (e.g. relevant computer programmes) were complex and perhaps only partially successfully navigated. However, the impact of engaging in this process can be seen in the appreciative language used throughout the study and adds credibility to the research findings.

\section{Participants}

Five birth mothers who had engaged with the birth relative counselling service (BRCS) provided by one adoption agency were recruited to participate in the study. The birth mothers were aged between 30 and 45. All were White British. The ages of their children ranged from 2 to 19 years. The number of children of the mothers' ranged from one to seven, the legal status range was from child protection orders (with children returned home) to full adoption orders and contact with children who were adopted or in foster care ranged from twice weekly to none. The birth mothers all chose their own pseudonym and these will be used throughout this report.

The counsellors of the BRCS were involved in carefully selecting who to approach for participation. It is likely that the sample was therefore biased towards those who have had a positive experience of counselling and who were deemed able and willing to fully engage with the research process. As this study was interested in the mechanisms of change and 'what works', this was considered appropriate. 
All the participants had received a substantial amount of support from the birth relatives counselling service. The service in question highly valued a person-centred approach and flexibility in format to take account of clients "fragility and chaotic lifestyles" (Pointon, 2008, p.14). The average number of counselling sessions the birth mothers had received, either by telephone or face to face, was 48.2, over an average period of 27 months. Three of the mothers were still receiving counselling at the time of their interviews and the remaining two requested to be put back on the waiting list when their counsellor made contact to ask about the research study.

The participants received counselling from two counsellors, one male and one female. In order to protect their anonymity both will be referred to as she or her from now on.

\section{Analysis}

Semi-structured interviews were audio-recorded and transcribed by the first author. The transcripts were analysed using Interpretative Phenomenological Analysis (Smith, Flowers and Larkin, 2009). A social constructionist approach was adopted which acknowledges the co-constructed nature of interview data and the role of the researcher in making sense of a phenomenon. The researchers remained close to the research question, and constructed meaning from the mothers' accounts within the context of their experiences of counselling, using that as a lens for all interpretation. A reflective diary was also utilised to enable the first author to remain aware of her own processes, perspectives and the effect the data had on her. The original transcripts were returned to often to ensure the themes being constructed were well-founded.

It has been suggested that the validation of findings are improved by working together with service users at the analysis stage of research (Allam et al., 2004, cited in Faulkner, 2012). In this study the research team worked closely with the expert by experience to check the validity of the codes and themes that emerged.

\section{Findings}

Three themes were constructed from the accounts of the birth mothers, namely, From feeling alone, judged and let down ... to feeling part of a special relationship, "The Healing Process" and "My Children are my world". These will now be discussed. 
From feeling alone, judged and let down...to feeling part of a special relationship

The first theme describes how the birth mothers came to feel a powerful sense of commitment and affection towards their counsellors. This is following many other difficult relationships with professionals and generally, as well as overwhelming experiences of judgement, powerlessness and mistrust in their lives before counselling.

There was a sense of the mothers initially finding themselves in a confusing and overwhelming system, and not knowing where to turn.

Saffron: Cos you just go through it and you just don't have a clue what's going on, and it's so confusing and then you've got all your emotions on top of it, and it's just like, I don't know, it's just, pretty

$$
\text { horrific... }
$$

In this context of feeling repeatedly let down, judged, and even deceived by other professionals, learning to trust their counsellors was important for all the mothers in the research. For example, Rebecca lists the many nameless 'workers' she has encountered before, who she not only felt were not on her side, but who she felt deceived her and let her down when she needed them most.

Rebecca: I had like different workers as well, different social workers, different workers, you know, and then I was like, everything was ok and the social workers had no concerns and these people had no concerns, ... then I didn't feel as if they wanted to come forward in the court and say there was nothing, 'we have no concerns over her', obviously you know 'she done her best'...

There was a sense that having come through care proceedings, their trust in professionals or those in authority had been badly damaged. Lara described a similar experience to Rebecca and linked this to how long it took her to trust her counsellor.

Lara: ...cos before I'd had people that told me, 'oh I'm working with you' when they weren't, they were, I felt like they were working against me to get evidence to take me kids. So, there's that issue to it as well, so like, the first like five or six appointments it took me to get to know her (counsellor)

In contrast to how the mothers described their experiences of other professionals, they spoke about their counsellors with a sense of warmth and affection, and all conveyed the message that their counsellors were important people in their lives. The strength of this relationship with their counsellors was richly described, notable in its difference to other nameless 'professional' relationships and all spoke about their counsellor in an exclusively positive light. 
Elisabeth: They make you feel... you're not on your own... they make you feel like, you know, you're the family; ... you're not just like, 'oh,

it's you, ok go on that side' - they don't make you feel like that. 'Oh yeah, come in! Would you like a cup of tea?', you know, they make you feel welcome.

In describing their counsellors as 'special' some also included examples of being made to feel special by their counsellor. In the context of the stigma experienced by the mothers elsewhere in their lives, feeling this way with their counsellors was novel, and appeared particularly significant. The mothers really appreciated the non-judgmental stance of their counsellors and acceptance of them for who they are. The impact of this is poignantly summed up by Lara in the following quote where she describes how she felt the moment she left hospital without her baby.

\section{Lara: when you're walking off ward and you've got your bags and you haven't got no baby yeah? Then what do you want to see in front of you? Someone that's offering you a hand going 'come on, it's going to be alright' (tearful). Cos that's what she does for me, that's what [my counsellor] did for me (crying).}

The theme Feeling alone, judged and let down to feeling part of a special relationship has contrasted the adverse experiences of 'help' offered to these mothers with the overwhelmingly positive experiences, for almost all the mothers, of their relationships with their counsellors. Taken together the quotes presented describe the journey each mother embarked on in moving from a wary to trusting relationship with her counsellor. It was not an easy journey for many of the mothers. However, once this trust had been established, the mothers were able to use counselling to create positive changes in their lives as described by the next theme, The healing process.

\section{"The Healing Process"}

Rebecca: ... way down it hurts but, the healing process starts...

This theme is a direct quote from Rebecca's interview that was conceptualised as capturing a key experience of all the mothers. They referred to a number of levels of change that occurred in relation to their experiences of counselling, highlighting some of the process/aspects of change that had occurred for them.

All of the mothers referred to significant experiences of trauma and/or abuse. For most this was either in their own childhoods or through more recent abusive relationships (or both). There was a sense for many that counselling provided a space to talk about these experiences and gain new understandings of how these may have significantly impacted on the removal of their children, either directly or indirectly. 
Rebecca: obviously I don't understand why they was bringing that up, that I was abused as a kid, because that has got nothing to $d$ - ok fair enough it might effect a little bit, about me raising my kids but obviously I didn't see...

For some counselling was also a space to make sense of the trauma of having their children removed. In line with the 'healing process' theme, Rebecca powerfully explained how she was helped to face up to what happened to her children and accept the emotional pain that goes with this by her counsellor (our emphasis).

Rebecca: .... where it hurts the most you get upset for and it really hurts, and obviously you tell the counsellor how much it hurts and when the pain and everything, and the emotional pain and stuff... she can help you heal that by talking to you and you can try and get the - she puts it in a way, where it doesn't hurt so much. It's coming to more of an understanding, and, she helps you through that emotional... pain.

Through talking about her own traumatic experiences in counselling and perhaps her counsellor normalising her responses to trauma, Lara seems to have come to reject the idea that she had mental health difficulties, preferring to think about what she experienced as a 'normal' reaction to the trauma of losing her children.

Lara: It's like they haven't helped me mental health through taking my kids off me, just made me worse... do you know what, it's like they say

I'm depressed, but I'm only depressed because I haven't got me babbies with me... but I've seen loads of mental health people, and they hadn't been able to help me - so is it really mental health or do you think that I've just like, I don't know, got into this like world where I just want my kids back, but I can't have 'em? (tearful)

For some, facing up to what had happened with their children also involved recognising the circumstances surrounding the children being removed and being helped by their counsellors to see that they did not hold all the responsibility. The accepting, nonjudgemental stance of the counsellors seems to have supported this process of meaningmaking.

Lara: Cos I suppose when you have your baby took off you, you feel like it's you, yeah? But it's not all you. And it's like, I don't know, they help you see that it's not all you.

Counselling also appeared to be a space where intense emotional experiences could be shared and acknowledged. The mothers made powerful references to the emotional impact of being separated from their children.

Rebecca: It didn't hit me until the final goodbyes. I felt like just... sitting on the floor and roaring my eyes out. I just wanted to just drop 
down like a heap of potatoes and just- that's it, my life was over. That is exactly how I felt - I felt my whole life has just disappeared, which to me it still feels like it has, because obviously there's nothing there, it was all dedicated, every single moment of time I had for the kids, and now they're just gone, it's just like, what do I do now?

For many, counselling was the first opportunity to really express these intense and overwhelming feelings and for their experiences to be acknowledged and validated.

All of the mothers referred to a sense that talking with their counsellors provided them with a means of 'getting things out' (Isobel, Saffron), 'spitting things out' (Lara) or things coming 'flooding out' (Rebecca). Some mothers described feeling things 'build up' inside of them before counselling.

Isobel: Cos it helps me a real big time a lot, counselling, talk about lots of things, cos it's in my brain you see, I think about everything and then it builds up, builds up, and then I've got to let it out.

Many mothers mentioned feeling that their counsellors understood them and what they had been through. Their histories of difficult relationships with professionals and societal stigmatisation following the removal of their children meant that 'feeling understood' in this context was experienced as particularly meaningful.

Rebecca: She worked it all out... it felt like she could read me quite easily, she knew, it felt like she knew me from the beginning... it felt as if she knew exactly how I felt, and she understood everything that I was saying...

All the mothers had noticed changes since having counselling. For many these included practical differences like going out more (Rebecca), having a routine (Saffron), getting a job (Elisabeth) or not returning to drug or alcohol use (Isobel, Lara). Many of the mothers spoke about changes in their relationships. For Elisabeth it wasn't just having a boyfriend that was different, it was having a boyfriend who cared about her and treated her well that was meaningful.

Elisabeth: They've really helped me with a lot of things, you know, my past, the violence, having my kids taken away from me, you know and now I've got myself a job and I've got myself a new partner - we've been together six years, and I'm happy...

Another difference the mothers had noticed was in how they felt in themselves. For many this involved a more hopeful sense of the future which was not present before counselling. For Saffron this hope was not in the context of life's challenges being gone, but rather within the context of her ongoing sadness. 
Saffron: It gave me a lot of perspective to sort of stand back and think ok, maybe I'm not... as bad, maybe there is a little bit more hope than I thought... now, I can go out, and I can say no, that it was my mental health, it's not, you know... I just think it made me realise it's not the end of my life so much, I can still have a life, but it's not... it'll never be as good obviously.

The theme The healing process encompasses the challenges and complex tasks faced by the mothers in reaching a more positive future. All the mothers in this study appeared to have made very good use of the opportunities counselling provided and, as evidenced by this theme, have been able to make significant changes in how they think, feel and relate to themselves and to others.

\section{"My Children are my world"}

This final theme, a direct quote from Lara's interview, captures the mothers' powerful and at times painful tussle with the notion of 'motherhood' in the absence of their children and in the context of using counselling as a space to talk about their children and connect to memories of being a mum. While the mothers found themselves in a range of different circumstances in relation to their children, what was common across all the mothers' accounts was a sense of the pain that connecting to their children in counselling brought with it, as well as a conflicted sense of being a mum.

\section{Lara: They're my world man, they're the reason why I can smile every day. All of them.}

All the mothers I spoke to used counselling to talk about the children that had been removed from their care. For the mothers whose children had been adopted, the lack of information available to them about where they were or what they were doing was reflected on often in counselling and their sadness or frustration at this situation was able to be expressed. For example, in thinking about the son she has not seen since he was a baby, Elisabeth describes how hard it is, given her lack of knowledge of his life. The extract below gives a sense of the unknown and ever-present questions in her mind. She expresses her wish to know more in such a way as to convey the feeling that she is not asking for much. Her final comment illustrates how she attempts to maintain her closeness with her missing son, through his blanket.

$$
\begin{gathered}
\text { Elisabeth: What's he look like now? How's he getting on at school } \\
\text { and...? You know? I don't want to like... I know he's with like, } \\
\text { adoption people now, yeah, and I don't want to wreck that. But I just } \\
\text { want... how, how's he getting on? And, how's school? You know like a } \\
\text { mother? It's not like I'm, you know, looking for him or whatever, I just } \\
\text { want a nice photo of him, you know?... I've still got his blanket, the } \\
\text { smell of him... }
\end{gathered}
$$


Isobel, in the absence of actual contact with her daughter, used counselling to develop and talk about their imagined relationship, had she not been adopted.

Isobel: I just wanna take her to school and, and if she's got any homework I got [my boyfriend] to help me... or, you know, something like that. I'd like to take her out, and bath her and take her [to] bed, and read her a story, something like that, it's just, that's what I say to [my counsellor], it's in my brain, you know.

Some mothers, who did have regular face-to-face contact with some of their children described feeling like they no longer knew their own children. Counselling was a place to talk about the pain this left them with.

Lara: So you go to one contact and he's there and he's little, so then you do little stuff with him, next time you see him he's big! And you don't know what to do with him, and it's like, you feel like you don't know your own kid, it's horrible.

Saffron illustrated the conflict experienced by many of the mothers in how their sense of being a mum is different with each of their children.

Saffron: It's really difficult... cos you don't feel like a Mum (tearful) ... er... I suppose just doing little things that I can still... I think with [my daughter] coming back, I'm able to be her Mum properly. So that makes me feel a lot better, because obviously I've got... someone to give all my affection to, if you know what I mean, but um, with the boys it's a little bit more difficult because... er, with [my eldest son] I feel like I'm his Mum still, because he's so affectionate and he wants that relationship so much. With [my youngest son] because he doesn't really remember so much, it's like a new relationship - there it's a bit strange. But I think we'll get there, it's just, you know... hopefully...

Again, counselling could be a place for the mothers to share these experiences within a validating context and to make sense of the thoughts and feelings that came with such experiences.

This theme has captured the strength and depth of feeling present in the accounts of the mothers regarding the children who had been removed from their care. These children were in the minds of their mothers often and counselling provided an outlet for the mothers to express their thoughts and feelings about their children. In connecting to these thoughts and memories the mothers are faced with questions about their identity as mothers. All the mothers described experiencing both feeling like a mum and not feeling like a mum at the same time. The conflict inherent in their position of being separated 
from their children however did not lessen the sense that for all the mothers their children are their 'world'.

The implications of this research will now be discussed.

\section{Clinical Implications}

The importance of therapeutic intervention for this vulnerable group

It has consistently been reported that birth mothers' psychological needs are not being met (Broadhurst \& Mason, 2017). This study points to the trauma experienced by birth mothers as a consequence of going through care proceedings, the deep suffering they experience due to being separated from their children, and the significant and ongoing impact on their lives. It also highlights the important impact counselling can have on the lives of these mothers. Therefore, it puts the spotlight on the necessity of consistently providing high quality, accessible and appropriate therapeutic support to birth mothers.

The study also points towards the key role of social workers in signposting and referring birth relatives to counselling or other forms of support. This tends to happen right at the point of relationship breakdown with professionals when birth relatives may be feeling at their lowest and most let down. Offering independent counselling at different times during and after care proceedings seems important. Local authorities should monitor uptake of services and work with independent counselling services to improve accessibility. Furthermore, flexibility in terms of how, where and for how long counselling is offered also seems vital (Nolte, Morgan \& Forbes, in press).

\section{The therapeutic relationship}

\section{"If poor relationships are where things emotionally go wrong then healthy relationships are where things can be put right" (Howe, 2008, p.161)}

The distress of birth relatives related directly to the loss of a child or children to the care system is likely to be something that never goes away (Neil, 2013). This study suggests that the process of child removal is traumatic and directly impacts on birth mothers' ability to form future trusting relationships with helping professionals. This is an important point and echoes the findings of Neil et al. (2010) that the forming of a 'special' relationship with a support worker, in this case counsellor, is fundamental to their ability to process what has happened to them and move forward with their lives.

The mothers in this study described nervousness and trepidation in meeting with their counsellors in the beginning. Given these mothers' previous negative experiences of relationships, both with professionals and in their lives generally, nervousness and 
trepidation would be warranted. Like the birth relatives interviewed by Neil and her colleagues (2010), many of the mothers in this study spoke of feeling betrayed by previous 'helping' professionals. It is understandable that these experiences would impact their beliefs about their new counsellors. Trauma theorists (e.g. Herman, 1992 cited in Dalenberg, 2004) agree that it is unreasonable to expect a traumatized client to quickly trust a professional helper. Therefore, work with birth mothers demands a specific and particular focus on the therapeutic relationship. Broadhurst and Mason (2014) identified access to "consistent professional, skilled help that nurtured the women's sense of resolve and self-regulation" as vital (p.1575). Price-Robertson, Obradovic and Morgan (2017) argue that achievements normally seen as personal, such as positive changes in self-perception and identity, can in fact be seen as interpersonal processes. It is "through social relationships" (p.7) that one is able to redefine one's experience - therefore they argue that recovery is relational. This fits well with the findings of the present study and the importance of the 'special relationship' in the first theme.

The exact nature of the 'special' relationship they experienced with their counsellors was something that the mothers seemed to struggle to define. The idea of a "critical friendship" with a professional as described by Cox et al. (2017) seems to fit well with what the mothers in this study described. Previous research has highlighted the need to provide a flexible service to birth relatives whose needs, situations and preferences are many and varied (Neil et al., 2010). Therefore, the way a counsellor relates to birth relatives might look slightly different from a more traditional therapeutic relationship. The mothers in this study valued the warm welcome they received at the counselling service which included for some a cup of tea or a cuddle. This was also a finding of the previous research by Neil et al. (2010) and relates to literature which explores how to 'warm the context' (Burnham, 2005) for therapy for people who hold a deep mistrust of professionals, as well as an idea that came from working with people living with HIV (where people may have multiple contextual issues) termed 'bending the frame' (Eversole, 1997). Bending the frame, according to Eversole (1997), describes a flexible approach to the therapeutic frame which addresses the complex and ever-changing circumstances of the client. This might involve going outside of the traditional setting, offering extended sessions, longer interventions or simply sharing a cup of tea. It could also mean making home visits, providing telephone counselling sessions, becoming an advocate or, in the case of one of the mothers in this study, helping to write a letter to her adopted child.

While the current study focused on the birth mothers' experiences of counselling, the findings, in line with Neil et al. (2010), also provide helpful suggestions of what might be most important in working with birth mothers more generally, e.g. within the social care system or generic mental health system. In particular, the importance of having a strong relational focus and investing in developing a trusting, validating therapeutic relationship ; furthermore, adopting a flexible and responsive approach, maybe at times putting aside convention, seems key. However, counsellors themselves have raised a note of caution, pointing out that the relevant levels of knowledge, training and experience are essential when working alongside birth relatives, to allow containment and responsiveness to the 
intensity, complexity and unique nature of their experiences (Nolte \& Forbes, in preparation).

\section{Counselling as a secure base}

The significance of the therapeutic relationship highlighted throughout this study can further be understood in terms of the creation of a 'secure base' as described by Bowlby (1988). Bolsover (2008) stated that talking in itself can function as a secure base, is therapeutic, and produces change. For this reason, those providing services for birth mothers have often prioritized nurturing relationships that allow for reciprocal conversations between practitioners and birth mothers (e.g. Lewis-Brooke et al., 2017).

Taking the idea of the therapist-client relationship as a potentially reparative attachment relationship a little further, Koch (1987) described being "consistent, available, [able to] interpret reality and meet concrete needs" (p.93) when working with a birth mother. She describes this "way of being" as more important than any promotion of "selfunderstanding through verbal communication" (p.94), or the more traditional mechanisms of change in counselling. Koch describes this as reparenting in the therapeutic relationship. It seemed to be difficult for the mothers in this study to articulate what it was their counsellors did to facilitate the therapeutic relationship. It is possible that the counsellors adopted a "way of being" as described by Koch, which was picked up by the mothers and which facilitated the forming of a reparative attachment relationship.

This has value beyond the phase of regular counselling. This study supports the idea that helping parents with the emotional pain of losing their children is not a 'quick fix' and so will take time (Broadhurst \& Mason, 2017). The importance of considering how the therapeutic relationship can endure after therapy ends (Zilberstein, 2008) has been established. Helping clients with this task, especially the more vulnerable clients who have experienced earlier, devastating losses, is important. Mahler, Pine and Bergman (1975, p. 69) described the concept of "emotional refuelling", where a mother remains a stable point that the child returns to before going off to explore again. They observed that through the smallest of, in the case of toddlers and mothers, physical contact, the child "perks up" (p.69). Bowlby relates the idea of a secure base to the therapeutic encounter, and the findings of this study, namely the value placed in the flexible, reliable and ongoing nature of the therapeutic relationship, could be thought of in terms of such 'refuelling'. One idea could be to build in opportunities for 'refuelling' between episodes of counselling. In this context, the use of telephone counselling could be viewed as an example of a 'small contact' that serves to 'perk up' the mothers, allowing them to feel confident facing the world on their own again.

\section{Finding unconditional positive regard}

Stigmatizing or blaming attitudes towards birth mothers are common within our society. Such attitudes have also been found amongst mental health professionals and social 
workers, e.g. where birth mothers are considered to have 'wronged', and therefore not be worthy of attention (e.g. Baran et al., 1977 cited in Logan, 1996). This highlights just how rare it may be for these mothers to experience 'unconditional positive regard' (Rogers, 1957). Such a stance adopted by the counsellors towards these mothers was experienced by many as novel, and profound. Broadhurst and Mason (2014) state that the quality of the professional-service user relationship is dependent on a "reciprocal positive dynamic", and where such a dynamic can be established it could be "transformative" in terms of outcomes for children and families (p.1575/6). The findings of this study again echo those of Neil and her colleagues (2010) in highlighting the value mothers place in being viewed not as 'deviant', but with 'positive regard' and with their experiences viewed in context. This poses an invitation to challenge society's dominant script of family and motherhood and carve a space for birth mothers to be seen, heard and acknowledged for the role they will inevitably still hold in children's lives.

\section{A social and trauma-informed model of psychological distress}

Neil (2013) rejects the pathologizing of birth mothers' distress, but instead sees it as a consequence of trauma, powerlessness and isolation from social support. She views the prevalence of experiences such as sickness, confusion, disorientation, anxiety, numbness, and depression amongst birth relatives as a "meaningful response" to an "adverse social experience" (p193). Logan (1996) makes a similar argument questioning data showing high levels of 'mental illness' among birth mothers and asking:

"are birth mothers any more seriously ill than other women or have they been inappropriately pathologized and constructed as mentally ill, victims of a patriarchal society which pathologizes women who fail to conform to society's expectations?" (p.622).

The findings of this research seem to suggest that a social model of distress may be a helpful framework to consider when working with birth mothers in a counselling setting. The mothers in this study seem to benefit from having their lives placed in a wider context and making connections between their experiences and what had happened in their lives, and the removal of their children.

Here the complex trauma the mothers described seem particularly important. Carolan et al. (2010) define complex trauma as "enduring, consistent, and ongoing victimisation throughout the lifespan" (p.172), a description which fits with the experiences of at least some of the mothers in this study, if not all of them. They report that women with trauma in their own childhoods, who go on to become the victims of adult partner violence, are more likely to be at risk of becoming perpetrators of neglect or abuse of their children, especially if protective factors such as family or community support and financial resources are lacking. Therefore, a trauma-informed approach to counselling seems essential. Support services for birth mothers should attend to their complex trauma histories and the systemic and intersecting effects of oppression due to low-income, poverty, and gender (Carolan et al., 2010). 
The findings also highlight the importance of addressing the trauma of care proceedings and the loss of children itself. Removal of children by court order has been compared to the 'death penalty' (Hewett, 1983, cited in Baden \& O'Leary Wiley, 2007). This sentiment was echoed in the findings of this study by the mothers expressing their devastation and heartache in response to the removal of their children. For some of the mothers in this study, they described that their 'life was over' as if they too had been given a death penalty. One mother, Elisabeth, even spoke of her attempt to take her own life in the wake of the devastation she felt after her children were removed.

\section{A multi-storied life}

The mothers in this study seemed to use counselling to explore other aspects of their lives and identities beyond being mothers whose children were removed from their care. From a Narrative therapy perspective this could be described as a 're-authoring' process (White, 2007). The mothers came to counselling feeling alone, overwhelmed and stigmatised. It could be argued that the adversarial nature of the child protection system and family court process had contributed to the 'dominant story' of these mothers' lives being one of negativity, failure and powerlessness. However, counselling seems to have enabled the mothers to strengthen an alternative storyline of love and devotion to their missing children, allowing them to situate themselves more fully and confidently within a preferred 'mother' identity.

The mothers described using counselling to talk about aspects of their lives now, opening up space for both the mother and non-mother aspects of their identities to be richly described and explored. Some of the mothers spoke of coming to see through counselling that their lives were not over, that they could 're-author' a life moving forward without their children. Thus, as White and Epston (1990) argued, a person's life is multi-storied and including experiences beyond the dominant experience of child removal is potentially healing.

\section{Strengths and Limitations}

This study went beyond a service evaluation of the effectiveness of a birth relative counselling service to explore the mechanisms of change in therapy and the impact counselling can have on wellbeing and on notions of identity and relationships. This study provides birth mothers' own first-person accounts of their experiences of counselling beyond child removal. This is not found anywhere else in the literature and so also represents a unique contribution to the field.

\section{Sample}

A significant limitation of the study is the failure to recruit any birth relatives who were not birth mothers to participate (including birth fathers). Recruitment with birth relatives 
is well documented to be challenging (e.g. Cox et al., 2017). The small size and convenience of the birth mother sample mean that the findings of this research cannot be statistically generalised beyond these clients. However, through what Smith et al. (2009) term theoretical generalisability, these findings point to important and evocative aspects for consideration for counselling offered to birth mothers in the future. The fact that all the participants are White British is also a limitation, especially given that statistics show that children of colour appear to be over-represented in the looked-after children population (DfE, 2017).

There remain birth relatives whose experiences are not present in research or literature. This study has not addressed the experiences of birth relatives other than mothers, it has not addressed the experiences of birth mothers who are not White, and it has not heard the experiences of birth mothers for whom counselling was not an option, e.g. birth mothers in prisons. Whilst clearly limitations, these omissions also represent some interesting opportunities for future research.

\section{Method}

One of the key aims of the project and an important reason for choosing a qualitative methodology was to privilege the voices of birth relatives themselves. This study has stayed close to the experiences as described by the five birth mothers who participated

and as such represents an important contribution in the context of 'silence' identified with regard the experiences of birth relatives. However, due to the nature of the methodology, and in line with the epistemological position of the authors, it should also be noted that what was expressed in the birth mothers' interviews may only represent one account coconstructed within one interview.

\section{Conclusions}

Child-centred services are clearly centre stage and the importance of protecting children from harm cannot be questioned. However, it could be argued that child-centred services are not the best way to protect children from harm. Why not family-centred services? Featherstone et al. (2016) point out that in reality social workers usually have responsibilities to more than one family member at a time. The findings of this study, support Broadhurst and Mason's (2013) call for an agenda focused on the needs of birth mothers. Evidence suggests many birth mothers (and other birth relatives) continue to have contact with the children who were removed, and some go on to parent subsequent children - therefore, supporting birth mothers will lead to better outcomes, not only for the children who have been removed, but also for future children as yet unborn. Children will suffer in the longer term if the needs of birth parents are ignored.

There are virtually no empirically validated guidelines for practice with birth relatives (Baden \& O'Leary Wiley, 2007). The findings of this study invite the provision of services for this client group that address the social and systemic nature of child removal, privilege the relational nature of recovery, empower birth mothers and create safe spaces 
for the processing of the emotional pain inherent in child removal. The findings of this study go some way towards answering Broadhurst et al. (2015)'s call to build the evidence of what this population of parents find helpful in terms of mental health intervention. It has raised the voices of five birth mothers with substantial experience of counselling following the loss of a child or children to adoption or foster care. Furthermore, this study represents new insights into the mechanisms of change within such counselling and what birth mothers themselves value within such interventions.

This study also invites a challenge to society's dominant script of family and motherhood and advocates a space for birth mothers to be seen, heard and acknowledged for the role they will inevitably still hold in children's lives and in society.

New Word count: 7486 (excluding abstract and references) 


\section{References}

BADEN, A.L. and O'LEARY WILEY, M., 2007. Counseling adopted persons in adulthood: Integrating practice and research. The Counseling Psychologist, 35(6), pp. 868-901.

BAUM, S. and BURNS, J., 2007. Mothers with learning disabilities: experiences and meanings of losing custody of their children. Tizard Learning Disability Review, 12(3), pp. 314.

BOLSOVER, N., 2008. Talking as a secure base: Towards the resolution of the Dodo verdict? Counselling Psychology Quarterly, 21(1), pp. 11-17.

BOWLBY, J., 1988. Clinical applications of attachment: A secure base. London: Routlege,.

BROADHURST, K., ALROUH, B., YEEND, E., HARWIN, J., SHAW, M., PILLING, M., MASON, C. and KERSHAW, S., 2015. Connecting events in time to identify a hidden population: Birth mothers and their children in recurrent care proceedings in England. The British Journal of Social Work, 45(8), pp. 2241-2260.

BROADHURST, K. and MASON, C., 2017. Birth parents and the collateral consequences of court-ordered child removal: Towards a comprehensive framework. International Journal of Law, Policy and the Family, 31(1), pp. 41-59.

BROADHURST, K. and MASON, C., 2014. Recurrent care proceedings: Part 3-birth mothers-against the odds-turning points for women who have lost children to public care. Family Law, 44, pp. 1572-1576.

BROADHURST, K. and MASON, C., 2013. Maternal outcasts: raising the profile of women who are vulnerable to successive, compulsory removals of their childrenâ€"a plea for preventative action. Journal of Social Welfare and Family Law, 35(3), pp. 291-304.

BRODZINSKY, D. and SMITH, S.L., 2014. Post-placement adjustment and the needs of birthmothers who place an infant for adoption. Adoption Quarterly, 17(3), pp. 165-184.

BURNHAM, J., 2005. Relational reflexivity: a tool for socially constructing therapeutic relationships. The space between: Experience, context and process in the therapeutic relationship.London: Karnac, , pp. 1-17.

CAROLAN, M., BURNS-JAGER, K., BOZEK, K. and ESCOBAR CHEW, R., 2010. Women who have their parental rights removed by the state: The interplay of trauma and oppression. Journal of Feminist Family Therapy, 22(3), pp. 171-186.

CARR, M.J., 2007. Birthmothers and subsequent children: The role of personality traits and attachment history. Journal of Social Distress and the Homeless, 9(4), pp. 339-348.

CHARLTON, L., CRANK, M., KANSARA, K. and OLIVER, C., 1998. Still Screaming: Birth parents compulsorily separated from their children. Manchester: After Adoption, .

COSSAR, J. and NEIL, E., 2010. Supporting the birth relatives of adopted children: How accessible are services? British Journal of Social Work, 40(5), pp. 1368-1386. 
COX, P., BARRATT, C., BLUMENFELD, F., RAHEMTULLA, Z., TAGGART, D. and TURTON, J., 2017. Reducing recurrent care proceedings: initial evidence from new interventions. Journal of Social Welfare and Family Law, 39(3), pp. 332-349.

DALENBERG, C.J., 2004. Maintaining the safe and effective therapeutic relationship in the context of distrust and anger: Countertransference and complex trauma. Psychotherapy: Theory, Research, Practice, Training, 41(4), pp. 438.

Department of Health, 2001. National Minimum Standards for England. Available at: http://webarchive.nationalarchives.gov.uk/+/www.dh.gov.uk/assetRoot/04/01/47/01/0401470 1.pdf

Department of Health., 2009. Research governance framework for health and social care.

EVERSOLE, T., 1997. Psychotherapy and counseling: Bending the frame. HIV mental health for the 21st century, , pp. 23-38.

FAULKNER, A. (2012). Participation and service user involvement. Qualitative Research Methods in Mental Health and Psychotherapy: A Guide for Students and Practitioners, , 3954.

FEATHERSTONE, BRID, GUPTA, A. and MILLS, S., 2016. The role of the social worker in adoption - ethics and human rights: an enquiry. Milton: Routledge Ltd.

FRAVEL, D.L., MCROY, R.G. and GROTEVANT, H.D., 2000. Birthmother perceptions of the psychologically present adopted child: Adoption openness and boundary ambiguity. Family Relations, 49(4), pp. 425-432.

HENDERSON, D.B., SASS, D.A. and CARLSON, J., 2007. Adoptees' and birth parents' therapeutic experiences related to adoption. Handbook of adoption: Implications for researchers, practitioners, and families, , pp. 379-397.

HOWE, D., 2008. The emotionally intelligent social worker. Palgrave Macmillan.

KOCH, P.M., 1987. Reparenting in the therapeutic relationship with a birth parent: A case. Child and Adolescent Social Work Journal, 4(3-4), pp. 89-96.

LEWIS-BROOKE, S., BELL, L., HERRING, R., LEHANE, L., O'FARRELL-PEARCE, S., QUINN, K. and SO, T., 2017. Mothers apart: an action research project based on partnership between a local authority and a university in London, England. Revista de Asistentã Socialã, (3), pp. 1-11.

LOGAN, J., 1996. Birth mothers and their mental health: Uncharted territory. The British Journal of Social Work, 26(5), pp. 609-625.

MAHLER, M.S., BERGMAN, A. and PINE, F., 1975. The psychological birth of the human infant. Symbiosis and individuation. London, Hutchinson, 1975.

MEMARNIA, N., NOLTE, L., NORRIS, C. and HARBORNE, A., 2015. 'It felt like it was night all the time': listening to the experiences of birth mothers whose children have been taken into care or adopted. Adoption \& Fostering, 39(4), pp. 303-317. 
NEIL, E., 2013. The mental distress of the birth relatives of adopted children: 'Disease' or 'unease'? Findings from a UK study. Health and Social Care in the Community, 21(2), pp. 191-199.

NEIL, E., 2006. Coming to terms with the loss of a child: The feelings of birth parents and grandparents about adoption and post-adoption contact. Adoption Quarterly, 10(1), pp. 1-23.

NEIL, E., 2000. The reasons why young children are placed for adoption: findings from a recently placed sample and a discussion of implications for subsequent identity development. Child \& Family Social Work, 5(4), pp. 303-316.

NEIL, E., COSSAR, J., LORGELLY, P. and YOUNG, J., 2010. Helping birth families: Services, costs and outcomes. British Association of Adoption and Fostering.

NOLTE, L. \& FORBES, C., in preparation. The experiences of counsellors in a service for birth relatives whose children have been adopted or taken into care. For submission to Adoption and Fostering.

NOLTE, L., MORGAN, H. and FORBES, C., in press. How best to support birth relatives what the experts say. In Understanding and Supporting Birth Parents whose Children have been Adopted. Jessica Kingsley Publishers.

POINTON and CLARE, 2008. After Adoption. Therapy today, (July), pp. 13-15.

POST-ADOPTION CENTRE, 2000. Thoughts on adoption by birth-mothers in contested adoptions.

PRICE-ROBERTSON, R., OBRADOVIC, A. and MORGAN, B., 2017. Relational recovery: beyond individualism in the recovery approach. Advances in Mental Health, 15(2), pp. 108120.

ROGERS, C.R., 1957. The necessary and sufficient conditions of therapeutic personality change. Journal of consulting psychology, 21(2), pp. 95.

SALVERON, M., LEWIG, K. and ARNEY, F., 2009. Parenting groups for parents whose children are in care. Child Abuse Review, 18(4), pp. 267-288.

SELLICK, C. (2007). An examination of adoption support services for birth relatives and for post-adoption contact in England and Wales. Adoption \& Fostering, 31(4), 17-26.

SLETTEBø, T., 2013. Partnership with parents of children in care: A study of collective user participation in child protection services. British Journal of Social Work, 43(3), pp. 579-595.

SMITH, J.A., FLOWERS, P. and LARKIN, M.H., 2009. Interpretative phenomenological analysis: Theory, method and research. Los Angeles; London: SAGE, 2009.

WHITE, M., 2007. Maps of narrative practice. WW Norton \& Company.

WHITE, M. and EPSTON, D., 1990. Narrative means to therapeutic ends. WW Norton \& Company. 
ZILBERSTEIN, K., 2008. Au revoir: An attachment and loss perspective on termination. Clinical Social Work Journal, 36(3), 301-311. 